\title{
User Acceptance Level of and Attitudes towards Telemedicine in the United Arab Emirates
}

A quantitative study

"Shaikha Abdool, ${ }^{1}$ Sherief Abdallah, ${ }^{2,3}$ Suhair Akhlaq, ${ }^{1}$ Hira Abdul Razzak ${ }^{1}$

\begin{abstract}
Objectives: This study aimed to examine acceptance levels of and attitudes towards telemedicine among users in the United Arab Emirates (UAE) and assess associations between perceived usefulness (PU), perceived ease of use (PEOU), attitudes towards use (ATU) and behavioural intention of use (BIU) in relation to telemedicine technology. Methods: This cross-sectional study used a simple random sampling design to obtain an appropriate sample from throughout the UAE. The technology acceptance model (TAM) and Rogers' diffusion of innovations (DOI) theory were applied as the conceptual basis for this study. An Arabic/English version of the questionnaire was distributed via email to physicians and nurses, members of the public (including patients), healthcare directors and information technology professionals. Data were collected from 1st March to 30th August 2019 and analysed using Statistical Package for the Social Sciences (SPSS). Results: A total of 330 participants were included (response rate: 85.7\%). BIU and PU were considered important elements of TAM in the adoption of telemedicine services compared to the other variables. The association between PEOU (beta $=0.033, P=0.692)$, PU (beta $=0.034 ; \mathrm{P}=0.679$ ) and ATU (beta $=0.055$; $P=0.421)$ in relation to telemedicine were positive but not significant. However, BIU was found to be a strong significant predictor of actual usage (beta $=0.224 ; P=0.003$ ). Conclusion: This study confirms TAM's applicability in the adoption of telemedicine services in the UAE. The results show that users' perceptions were significantly related to their behavioural intention to use telemedicine. Factors influencing telemedicine technology are likely to vary as technology acceptance in other geographical areas may differ from the sample presented here.
\end{abstract}

Keywords: Telemedicine; Patient Acceptance of Healthcare; Attitude; Behaviour; Intention; United Arab Emirates.

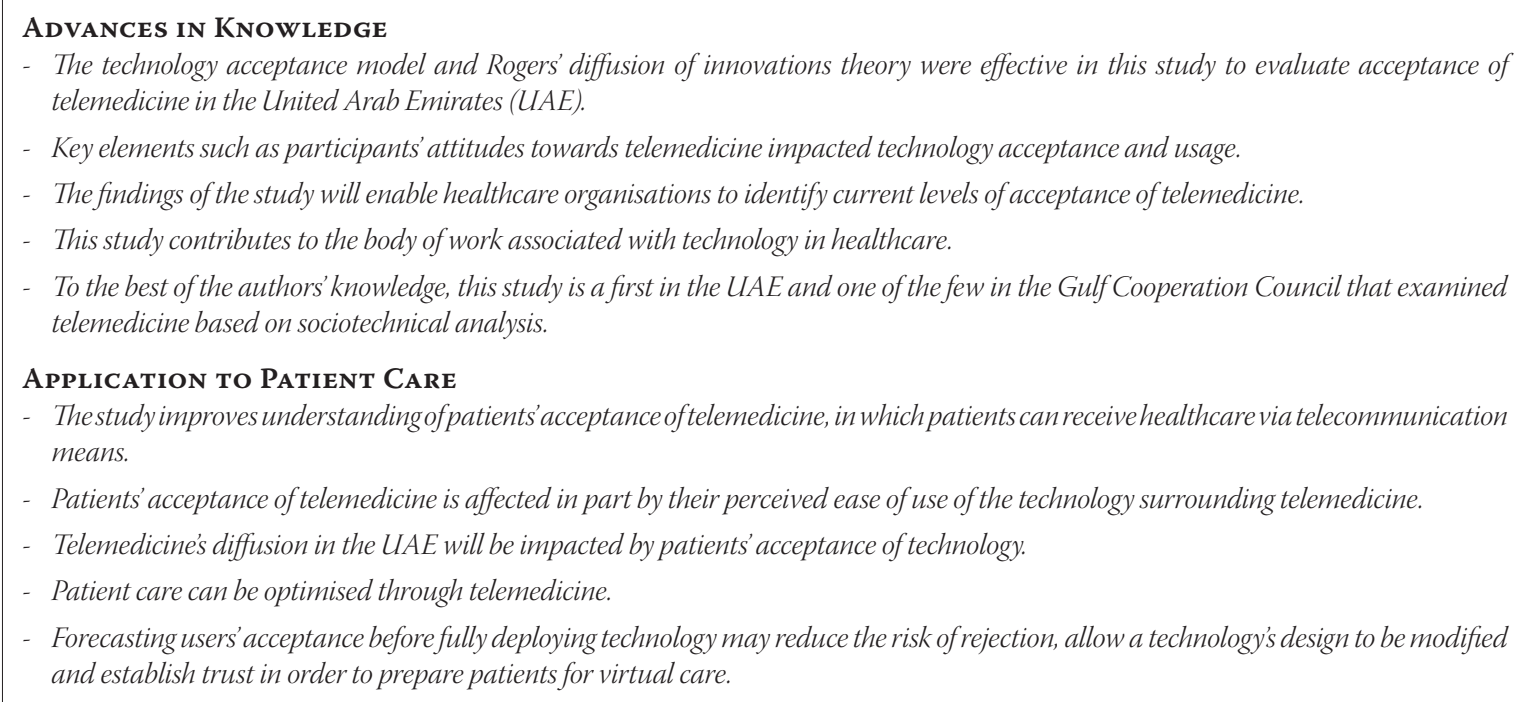

\section{$\mathrm{T}$} Elemedicine has BeEn DeFined as an exchange of medical information from a distance and the use of communications and electronic technologies to support and provide healthcare when distance separates the participants. ${ }^{1}$ The information exchanged in telemedicine can be image-based, voice files, a series of commands to a surgical robot or elements of medical records. ${ }^{2}$ In the past, telemedicine focused exclusively on comm- unication between medical experts in remote geographical locations. At present, though, telemedicine programmes are going beyond their traditionally educational roles and have shifted into the arena of clinical care to improve overall healthcare outcomes. Although the application of this technology is still in its infancy, the medical community is enthusiastic about using telemedicine with patients throughout the United Arab Emirates (UAE). ${ }^{3}$ 
Telemedicine has great potential to support healthcare for disease management. Medical care delivered through telemedicine will reduce length of stay (LOS), visits and related costs of the healthcare institutions. ${ }^{4}$

The technology behind telemedicine is multifaceted and requires in-depth evaluation. To ensure acceptance and diffusion of telemedicine, vast human and capital resources and effort are needed to comprehend it appropriately. TAM was developed by Fred Davis in the late 1980s and is mainly used in the information systems discipline to address users' acceptance and use of technology. DOI theory was developed by Everett Rogers in 1962 and has been used in multiple disciplines, including sociology and anthropology. ${ }^{5}$ The aim of the DOI theory is typically to help researchers understand the spread of a new idea or technology by answering how, why and what. TAM and the DOI theory have been used together in research in medical and non-medical fields. For instance, Cowen applied TAM to evaluate computed radiography systems, while Mutahar et al. addressed mobile banking services in Yemen by applying TAM and the DOI theory. ${ }^{6,7}$ TAM includes perceived usefulness (PU) and perceived ease of use (PEOU) leading to attitudes towards use (ATU), behavioural intention to use (BIU) and actual use (AU).

Telemedicine has a number of advantages over traditional face-to-face approaches to medicine. But it is nonetheless essential to examine users' opinions and knowledge regarding this technology before starting a telemedicine programme. ${ }^{8,9}$ Additionally, healthcare professionals' perceptions and knowledge are essential influencers of a programme's success. ${ }^{10-12}$ Previous studies have revealed that a lack of training and skills in healthcare providers and a lack of knowledge among users are barriers to telemedicine utilisation. ${ }^{13,14}$ Initial costs and a deficiency of technical expertise and reimbursement of capital costs have also emerged as obstacles in utilisation of telemedicine. ${ }^{15}$ Additionally, appropriate telemedicine technological understanding specifically by healthcare professionals is required for successfully implementing and deploying technology. ${ }^{9}$ The more capabilities with and knowledge of telemedicine users have, the more optimistic they are about such technology. ${ }^{16}$

Previous studies have demonstrated an understanding of telemedicine among patients and clinical staff. Meher et al. suggested that patients and physicians should increase their awareness and utilisation of telemedicine. ${ }^{17}$ El Gatit et al. found that $48.8 \%$ of patients had a fair understanding of telemedicine, $12.2 \%$ of the physicians had limited knowledge of telemedicine and 39\% had a higher level of telemedicine-related understanding. ${ }^{18}$ The familiarity of professionals regarding telemedicine impacted their attitudes towards the utilisation of telemedicine technology. ${ }^{19}$

This study aimed to evaluate the user's acceptance level and attitudes towards telemedicine in the UAE along with studying the association between PEOU, PU, ATU and BIU and the actual usage of telemedicine technology. The results of the study will be valuable for practitioners in the UAE and can also be used in fields outside healthcare.

\section{Methods}

This cross-sectional study was conducted from $1^{\text {st }}$ March to $30^{\text {th }}$ August 2019 using a simple random sampling approach design throughout the UAE. Using this technique, every member of the population had the same probability of being selected and is an appropriate approach when inferences are to be made from a large population. The randomly selected target population included physicians and nurses $(\mathrm{n}=98)$, members of the public including patients $(n=215)$ and healthcare directors and information technology professionals $(\mathrm{n}=17)$. The sample size was calculated using a Raosoft calculator (Raosoft, Inc., Seattle, Washington, USA) and the services of Select Statistical Services Limited (Exeter, UK). Sample size was calculated based on a population size of 8,093,766 (ages 18+) with a $5 \%$ margin of error at a $95 \%$ confidence interval (CI). Therefore, the recommended sample size was 385 participants. This study included participants who were $\geq 18$ years old, spoke both Arabic and English, were competent enough to participate without any assistance and had proper intellectual and mental capabilities. Critically ill patients were excluded from the study.

TAM and the DOI theory were applied to this study. DOI theory elements were added to the TAM as external factors impacting telemedicine acceptance. The implementation of models and theories in this research followed prototype testing/system selection procedures. The resulting Arabic/English language questionnaire was distributed via email and evaluated the participants' reactions to the telemedicine technology via a series of questions which were designed to measure possible users' demand for telemedicine, acceptance level of technology use, attitude and BIU towards telemedicine, as well as PU and PEOU because these constructs have been identified as accurate predictors of users' intention to use technology. ${ }^{20}$ Usage frequency was also measured. Validated questions from previous research were adapted to measure the applied model and theory in this research. ${ }^{19,20}$ Cronbach alpha of 0.8 indicated an acceptable level of reliability. A five-point 
Table 1: Demographic characteristics of the study population $(\mathrm{N}=330)$

\begin{tabular}{|c|c|}
\hline Characteristic & n (\%) \\
\hline \multicolumn{2}{|l|}{ Gender } \\
\hline Male & $152(46.1)$ \\
\hline Female & $178(53.9)$ \\
\hline \multicolumn{2}{|l|}{ Age group in years } \\
\hline $18-25$ & $29(8.8)$ \\
\hline $26-35$ & $124(37.6)$ \\
\hline $36-45$ & $118(35.8)$ \\
\hline $46-55$ & $44(13.3)$ \\
\hline $56-65$ & $15(4.5)$ \\
\hline \multicolumn{2}{|l|}{ Nationality } \\
\hline Emirati & $162(49.1)$ \\
\hline Non-Emirati & $168(50.9)$ \\
\hline \multicolumn{2}{|l|}{ Education } \\
\hline Basic education & $30(9.1)$ \\
\hline Undergraduate & $215(65.2)$ \\
\hline Postgraduate & $85(25.8)$ \\
\hline \multicolumn{2}{|l|}{ Place of Residence } \\
\hline Dubai & $136(41.2)$ \\
\hline Sharjah & $78(23.6)$ \\
\hline Ajman & $43(13.0)$ \\
\hline Abu Dhabi & $34(10.3)$ \\
\hline Umm Al Quwain & $13(3.9)$ \\
\hline Ras Al Khaimah & $10(3.0)$ \\
\hline Fujairah & $16(4.8)$ \\
\hline
\end{tabular}

Likert-scale questionnaire was designed on the basis of the literature review. The scale ranged from Strongly disagree (1) to Strongly agree (5). Based on participants' agreement levels on a Likert scale, responses were pooled during analysis as 'strongly agree' and 'agree' indicating agreement; 'strongly disagree' and 'disagree' indicating disagreement and neutral responses were kept as it is. Scores for all questions for each perceived telemedicine attribute were averaged to generate a precise mean score.

IBM Statistical Package for the Social Sciences (SPSS), Version 25.0, New York, United States was used to analyse descriptive statistics. Mean \pm standard deviation (SD) was calculated for continuous variables, while percentages and frequencies were calculated for categorical variables. Multiple linear regression was performed to measure the association between actual usage and PU, PEOU, ATU and BIU. Regression analysis was carried out to determine statistical significance and examine the predictability potential of the independent variables (PU, PEOU, ATU and BIU) on the dependent variable (AU). Stepwise model selection was used. A $P$ value $\leq 0.05$ was considered statistically significant. The $P$ values provided helpful information in choosing a model. The potential collinearity among variables using variance inflation factors (effect modifiers) was tested for assumptions.

The UAE's Ministry of Health and Prevention Research Ethics Committee (Approval Reference No: MOHP/REC-3/2018) and the British University in

Table 2: Knowledge of, acceptance of (i.e. perceived usefulness and perceived ease of use), attitude towards and behavioural intention to use telemedicine $(\mathrm{N}=330)$

\begin{tabular}{|c|c|c|c|c|c|}
\hline \multirow[t]{2}{*}{ Category } & \multirow[t]{2}{*}{ Statement } & \multicolumn{3}{|c|}{ n (\%) } & \multirow[t]{2}{*}{ Mean $\pm \mathrm{SD}$} \\
\hline & & $\begin{array}{l}\text { Strongly disagree } \\
\text { and disagree }\end{array}$ & Neutral & $\begin{array}{l}\text { Strongly agree } \\
\text { and agree }\end{array}$ & \\
\hline General & Telemedicine is a well-known concept. & $162(49.1)$ & $71(21.5)$ & $97(29.4)$ & $2.73 \pm 1.14$ \\
\hline \multirow[t]{2}{*}{ PU } & $\begin{array}{l}\text { Telemedicine would allow tasks to be } \\
\text { accomplished more quickly than traditional } \\
\text { care. }\end{array}$ & $30(9.1)$ & $53(16.1)$ & $247(74.8)$ & $3.83 \pm 0.91$ \\
\hline & $\begin{array}{l}\text { Using telemedicine would improve } \\
\text { healthcare performance. }\end{array}$ & $32(9.7)$ & $79(23.9)$ & $219(66.4)$ & $3.69 \pm 0.91$ \\
\hline \multirow{2}{*}{ PEOU } & $\begin{array}{l}\text { It would be easy for me to become skilful at } \\
\text { using telemedicine. }\end{array}$ & $41(12.4)$ & $77(23.3)$ & $212(64.3)$ & $3.62 \pm 0.99$ \\
\hline & Telemedicine would be easy to use. & $41(12.4)$ & $101(30.6)$ & $188(56.9)$ & $3.55 \pm 0.92$ \\
\hline ATU & $\begin{array}{l}\text { Telemedicine would be better than } \\
\text { traditional medical care delivery. }\end{array}$ & $110(33.3)$ & $89(27.0)$ & $131(39.7)$ & $3.05 \pm 1.15$ \\
\hline $\mathrm{BIU}$ & I will use telemedicine on a regular basis. & $85(25.8)$ & $108(32.7)$ & $137(41.5)$ & $3.17 \pm 0.99$ \\
\hline
\end{tabular}

$S D=$ standard deviation; $U A E=$ United Arab Emirates; $P U=$ perceived usefulness; $P E O U=$ perceived ease of use; $A T U=$ attitude towards use; $B I U=$ behavioural intention of use. 
Table 3: Distribution of responses to statement/questions regarding the use of telemedicine in the United Arab Emirates $(\mathrm{N}=330)$

$\begin{array}{lc}\text { Statement/question } & \mathbf{n}(\%) \\ \text { Frequency of telemedicine use } & \\ \text { Regularly } & 26(7.9) \\ \text { Often } & 88(26.7) \\ \text { Rarely } & 72(21.8) \\ \text { Not at all } & 64(19.4) \\ \text { Don't know } & 80(24.2) \\ \text { Which of telemedicine's features have you mostly used or } \\ \text { will probably use?* } \\ \text { Reports generation } & 120(36.4) \\ \text { Scheduler } & 87(26.4) \\ \text { Export/import files } & 116(35.2) \\ \text { Online help } & 162(49.1) \\ \text { Other } & 6(1.8) \\ \text { What features of telemedicine do you most like?* } & 135(40.9) \\ \text { Virtual communication } & 117(35.5) \\ \text { Sharing reports } & 180(54.5) \\ \text { Booking an appointment without } & \\ \text { visiting the hospital } & 152(46.1) \\ \text { Accessing personal medical record } & 8(2.4) \\ \text { Other } & 163(49.4) \\ \text { What features of telemedicine do you most dislike?* } & 66(20.0) \\ \text { Risk of sudden Internet disconnection } & 94(28.5) \\ \text { User interface } & 125(37.9) \\ \text { Language } & 17(5.2) \\ \text { Technical skills required } & \\ \text { Other } & \\ & \end{array}$

"Participants could choose multiple options.

Dubai Research Ethics Committee granted ethical approvals. Prior to completing the questionnaire, individuals signed a consent form. Participation was completely voluntary with no obligations, penalties or risks for participation or withdrawal from the study. Confidentiality and anonymity of the participants was maintained.

Table 4: Correlation matrix of the study variables

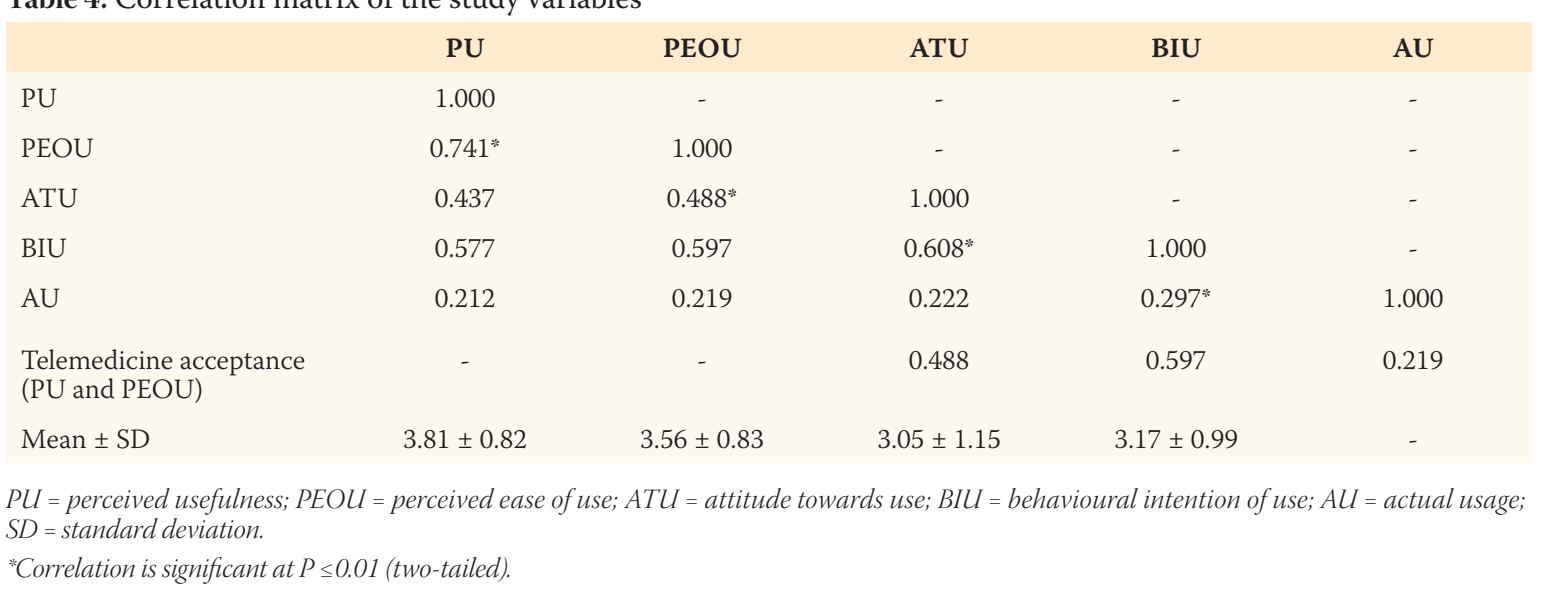

\section{Results}

A total of 330 participants completed the questionnaire (response rate: $85.7 \%$ ) and were included in this study with a mean age of $37.56 \pm 9.43$ years (range: 18-65). In total, 152 (46.1\%) males and 178 (53.9\%) females were included. There was an almost equal distribution of Emiratis and non-Emiratis who participated $(49.1 \%$ versus $50.1 \%$, respectively). Most of the respondents were 26-35 years old ( $n=124 ; 37.6 \%$ ) followed by those aged $36-45$ years old $(\mathrm{n}=118 ; 35.8 \%)$. In terms of education levels, most of the participants had completed undergraduate education ( $\mathrm{n}=215 ; 65.2 \%$ ) followed by those who had earned a post-graduate degree $(\mathrm{n}=85 ; 25.8 \%)$. A minority ( $n=30 ; 9.1 \%$ ) of participants had only completed basic education.

Participants from Dubai formed the majority of the sample $(\mathrm{n}=136 ; 41.2 \%)$ followed by Sharjah $(\mathrm{n}=78$; 23.6\%), Ajman ( $n=43 ; 13.0 \%)$, Abu Dhabi $(n=34 ; 10.3 \%)$, Al-Fujairah ( $\mathrm{n}=16 ; 4.8 \%$ ), Umm Al-Quwain ( $=13$; 3.9\%) and Ras Al-Khaimah ( $\mathrm{n}=10 ; 3.0 \%)$ [Table 1].

The highest mean score for general knowledge of telemedicine was recorded for the statement "there is evident use of advanced technology in the UAE" (4.04 \pm 1.08 ). The lowest mean score for general knowledge was for the statement "telemedicine is a well-known concept" (2.73 \pm 1.14$)$. The majority of participants (80.6\%) agreed "there is evident use of advanced technology in the UAE". The statement "there is a need for telemedicine in the UAE" received a mean score of $3.71 \pm 1.02$ with most respondents (70.9\%) agreeing with the statement [Table 2].

With respect to the AU of telemedicine, participants responded most frequently that they would use it often ( $n=88 ; 26.7 \%$ ) or did not know whether they would use it ( $\mathrm{n}=80 ; 24.2 \%)$. Less frequently, users indicated that they would use telemedicine rarely $(\mathrm{n}=72$; $21.8 \%)$, notatall $(n=64 ; 19.4 \%)$ or regularly $(n=26 ; 7.9 \%)$. Almost half of participants $(n=162 ; 49.1 \%)$ indicated that online help would be the telemedicine feature 
Table 5: Multivariate regression analysis of the study variables

\begin{tabular}{lccccc} 
Model $^{*}$ & \multicolumn{2}{c}{ Unstandardised coefficients } & $\begin{array}{c}\text { Standardised } \\
\text { coefficients }\end{array}$ & t value & P value \\
& B & SE & Beta & & 0.471 \\
(Constant -Actual Use) & 0.244 & 0.338 & & 0.722 & 0.679 \\
PU & 0.053 & 0.128 & 0.034 & 0.415 & 0.692 \\
PEOU & 0.052 & 0.131 & 0.033 & 0.397 & 0.421 \\
ATU & 0.062 & 0.077 & 0.055 & 0.806 & 0.003 \\
BIU & 0.292 & 0.099 & 0.224 & 2.963 &
\end{tabular}

$P U=$ perceived usefulness; $P E O U=$ perceived ease of use; $A T U=$ attitude towards use; $B I U=$ behavioural intention of $u s e ; S E=$ standard error . ${ }^{*} R^{2}=0.093$ and adjusted $R^{2}=0.082$; Dependent variable was the frequency of actual use.

Table 6: Characteristics associated with acceptance of telemedicine among users in the United Arab Emirates

\begin{tabular}{|c|c|c|c|c|c|c|}
\hline \multirow[t]{2}{*}{ Characteristic } & OR (95\% CI) & \multirow{2}{*}{$\begin{array}{c}P \\
\text { value }\end{array}$} & OR (95\% CI) & \multirow{2}{*}{$\begin{array}{c}P \\
\text { value }\end{array}$} & OR (95\% CI) & \multirow{2}{*}{$\begin{array}{c}P \\
\text { value }\end{array}$} \\
\hline & Positive attitude & & $\begin{array}{c}\text { Positive behavioural } \\
\text { intention }\end{array}$ & & Effective use & \\
\hline $18-30$ years old & $2.167(0.803-5.844)$ & 0.127 & $1.716(0.583-5.051)$ & 0.327 & $1.885(0.709-5.016)$ & 0.204 \\
\hline $31-40$ years old & $1.866(0.735-4.735)$ & 0.189 & $1.423(0.517-3.916)$ & 0.494 & $1.522(0.606-3.827)$ & 0.372 \\
\hline $41-50$ years old & $1.426(0.528-3.855)$ & 0.484 & $0.890(0.300-2.645)$ & 0.834 & $1.138(0.426-3.043)$ & 0.797 \\
\hline Male & $0.871(0.548-1.385)$ & 0.559 & $0.959(0.575-1.601)$ & 0.874 & $0.853(0.542-1.345)$ & 0.853 \\
\hline Emirati & $1.379(0.867-2.193)$ & 0.174 & $1.301(0.780-2.170)$ & 0.313 & $1.359(0.861-2.145)$ & 0.187 \\
\hline Basic education & $1.117(0.462-2.704)$ & 0.805 & $1.573(0.599-4.133)$ & 0.358 & $1.469(0.611-3.534$ & 0.391 \\
\hline Undergraduate education & $0.725(0.423-1.242)$ & 0.242 & $0.805(0.443-1.461)$ & 0.476 & $0.844(0.500-1.427)$ & 0.527 \\
\hline Diffusion of innovations & $4.805(2.855-8.085)$ & $<0.001$ & $3.851(2.201-6.736)$ & $<0.001$ & 5.743 (3.411-9.668) & $<0.001$ \\
\hline
\end{tabular}

$O R=$ odds ratio; $C I=$ confidence interval .

most likely to be used, whereas the most liked features included booking an appointment easily without visiting the hospital ( $\mathrm{n}=180 ; 54.5 \%)$, accessing personal medical records ( $\mathrm{n}=152 ; 46.1 \%)$, communicating virtually $(\mathrm{n}=135 ; 40.9 \%)$ and sharing reports ( $\mathrm{n}$ $=117$; 35.5\%). Most respondents $(\mathrm{n}=163 ; 49.4 \%)$ indicated that fear of sudden Internet disconnection was the most disliked aspect of telemedicine [Table 3].

The mean score for PEOU was $3.56 \pm 0.83$, suggesting that telemedicine would be easy to use. The mean score for the question of whether delivering care via telemedicine would be better than care delivered traditionally was $3.05 \pm 1.15$ (ATU) and participants indicated that they would use telemedicine on a regular basis with a mean score of $3.17 \pm 0.99$ (BIU). A strong significant positive correlation was detected between PEOU and PU ( $\mathrm{r}=0.741 ; P<0.01)$. This finding indicates that when users find the system easy to use, then the PU of that system intensifies. Similarly, a significant strong positive correlation was found between PEOU and ATU $(r=0.488 ; P<0.01)$. ATU and BIU also demonstrated a strong positive correlation $(\mathrm{r}=0.608 ; P<0.01)$. A weak but still significant positive relationship was found between BIU and AU $(r=0.297$; $P<0.01)$ [Table 4].

The model of regression found BIU was a strong significant predictor of $\mathrm{AU}$ (beta $=0.224 ; P=0.003$ ). PEOU (beta $=0.033 ; P=0.692), \mathrm{PU}($ beta $=0.034 ; P=0.679$ ) and ATU (beta $0.055 ; P=0.421$ ) were not significant predictors of AU. The results indicate that the variables that were measured describe $8.2 \%$ of the dependent variable for actual usage [Table 5].

In terms of characteristics associated with acceptance of telemedicine, there were no significant differences between age groups. Emirati participants had a 1.379 probability of accepting telemedicine and had a positive attitude (95\% CI: 0.867-2.193), positive behavioural intention (odds ratio [OR]: 1.301, 95\% CI: 0.780-2.170) and effective usage (OR: 1.359, 95\% CI: 0.861-2.145); however, there was no statistically significant difference. Furthermore, being male and having a higher level of education was found to have no effect on the association between a positive attitude, positive behavioural intention and effective use of telemedicine on the acceptance of telemedicine. However, participants had a greater probability for 
the confounding variable of diffusion of innovation when they responded with strongly agree or agree to accept telemedicine (OR $=4.805$, 95\% CI: 2.855-8.085; $P<0.001)$. In addition, diffusion of innovations had a statistically significant relationship with positive behavioural intention $(\mathrm{OR}=3.851,95 \%$ CI: 2.201-6.736; $P<0.001)$ or effective use of telemedicine $(\mathrm{OR}=5.743$, 95\% CI: 3.411-9.668; $P<0.001)$ [Table 6].

\section{Discussion}

This study assessed users' acceptance levels of and attitudes towards telemedicine in the UAE and determined the association between PEOU, PU, ATU and BIU towards the AU of telemedicine. The results of this study indicate a strong positive correlation between PU and PEOU. This finding implies that the easier users find the system to use, the more they consider it beneficial and vice versa. Previous studies found a similar correlation between PEOU and PU. ${ }^{6,19,21}$ Furthermore, this finding suggests that the TAM tends to position PEOU and PU as two different antecedents towards using technology due to their positive correlation.

A significant positive correlation was found between PEOU and ATU. Respondents were more likely to form a positive attitude towards utilising the system when it was confirmed as useful through practice and vice versa. These findings were consistent with previous findings that indicated that equal acceptance was associated with attitude. ${ }^{22}$ Previous studies have also found that PU was highly correlated with attitude, but PEOU had a relationship that did not reach statistical significance. ${ }^{19,21}$

The findings of the current study revealed that ATU and BIU demonstrated a strong positive correlation. This suggests that if users tend to have positive attitudes towards utilising the system, then actual system usage becomes much easier. This attitude is a factor contributing to BIU telemedicine and was also evident in previous studies. ${ }^{22,23}$ A weak positive relationship was also observed in the current study between BIU and AU. This relationship between BIU technology and AU requires further exploration to rectify the high level of focus on BIU, otherwise known as the 'bottleneck' problem. ${ }^{24}$

Results of the current study on the regression model presented $8.2 \%$ of the observed variance in actual usage being a dependent variable. This study's findings were contrary to those of a previous study which stated that in any organisation, a system can be adopted if it is considered to be useful and offers direct benefits, regardless of attitudes. ${ }^{25}$ Thus, if new technology is useful compared to what the users have been using to perform their daily activities then other factors such as PEOU and attitudes are considered secondary. ${ }^{26}$ These findings are contrary to the results of prior research in which attitude emerged as the most authoritative predictor of system use. ${ }^{27}$ The results of the study suggest that telemedicine can be introduced in the UAE if key elements are considered to ensure acceptance and effective usage. However, decision-makers need to consider other aspects of technology including its strengths and obstacles to increase acceptance.

While this research had strengths, it also had limitations. While the cross-sectional design was useful for the UAE's context, evaluating technology at a single point in time means that it is highly likely that people's attitude towards and acceptance of technology may change or have changed over time. This possibility is especially prevalent after a period of technology exposure.

\section{Conclusion}

This research examined telemedicine acceptance in the UAE. The associations PEOU and ATU in relation to telemedicine technology tested were found to be positively correlated. BIU was considered the strongest predictor of telemedicine AU compared to ATU and PEOU. In addition, results suggest that BIU is essential but the usefulness of a system is even more important and should not be ignored. An individual's perception of the ease of using telemedicine is significantly associated with their intention to use telemedicine. Further empirical studies should measure telemedicine technology's impact on patients' health outcomes and expenditures over time. Moreover, a combination of models (e.g. TAM and task-technology fit) should be applied to future research to understand and classify common aspects along with the underlying determinants of behavioural intentions to compare the results of the models used. Future researchers should attempt to analyse and gather both data for objective use and self-reported perceptions. These types of data will further guide solving lingering questions with respect to TAM constructs along with their relationship to past TAM research.

\section{CONFLICT OF INTEREST}

The authors declare no conflicts of interest.

\section{FUNDING}

No funding was received for this study. 


\section{References}

1. Chen ET. Improving patient care with telemedicine technology In: McHaney RW, Reychev I, Azuri J, McHaney ME, Moshanov R. Impacts of information technology on patient care and empowerment. 1st ed. Pennsylvania: IGI Global, 2019. pp. 1-18.

2. Shah TK, Tariq T, Phillips R, Davison S, Hoare A, Hasan SS, et al. Health care for all: Effective, community supported, healthcare with innovative use of telemedicine technology. Pharm Policy Pract 2018; 11:3. https://doi.org/10.1186/s40545018-0130-5.

3. Al-Qirim N. Realizing telemedicine advantages at the national level: Cases from the United Arab Emirates. Telemed J E Health 2007; 13:545-55. https://doi.org/10.1089/tmj.2006.0087.

4. Armaignac DL, Saxena A, Rubens M, Valle CA, Williams LM, Veledar E, Gidel LT. Impact of telemedicine on mortality, length of stay, and cost among patients in progressive care units: experience from a large healthcare system. Crit Care Med 2018; 46:728. https://doi.org/10.1097/CCM.0000000000002994

5. Kaminski J. Diffusion of innovation theory. Can J Nurs Inform 2011; 6:1-6.

6. Cowen JB. The influence of perceived usefulness, perceived ease of use, and subjective norm on the use of computed radiography systems: A pilot study. From: www.kb.osu.edu/ dspace/bitstream/handle/1811/36983/?sequence $=1$ Accessed: Jul 2020.

7. Mutahar AM, Daud NM, Thurasamy R, Isaac O, Abdulsalam R. The mediating of perceived usefulness and perceived ease of use: the case of mobile banking in Yemen. Int J Technol Diffusion (IJTD) 2018; 9:21-40. https://doi.org/10.4018/IJTD.2018040102.

8. Hayavi HMH, Alipour J, Mastaneh Z, Mouseli L. Feasibility study of telemedicine implementation in Hormozgan University of Medical Sciences. Hormozgan Med J 2011; 15:128-37.

9. Judi HM, Razak AA, Sha'ari N, Mohamed H. Feasibility and critical success factors in implementing telemedicine. Inf Technol J 2009; 8:326-32. https://doi.org/10.3923/itj.2009.326.332.

10. Au L. Assessing the potential needs for telehealth in Papua New Guinea (PNG). MSc Thesis, 2009, University of Canterbury, Canterbury, New Zealand.

11. Ibrahim MI, Phing CW, Palaian S. Evaluation of knowledge and perception of Malaysian health professionals about telemedicine. J Clin Diagn Res 2010; 4:2052-6.

12. MacNeill V, Sanders C, Fitzpatrick R, Hendy J, Barlow J, Knapp M, et al. Experiences of front-line health professionals in the delivery of telehealth: A qualitative study. Br J Gen Pract 2014; 64:e401-7. https://doi.org/10.3399/bjgp14X680485.

13. Almathami HK, Win KT, Vlahu-Gjorgievska E. Barriers and facilitators that influence telemedicine-based, real-time, online consultation at patients' homes: systematic literature review. J Med Internet Res 2020; 22:e16407.
14. Scott Kruse C, Karem P, Shifflett K, Vegi L, Ravi K, Brooks M. Evaluating barriers to adopting telemedicine worldwide: A systematic review. J Telemed Telecare 2018; 24:4-12.

15. Khammarnia M, Torani S, Mohamadi R. Feasibility of remote medical consultation implementation in Iran University of Medical Sciences. Eur J Med Res 2010; 15:199

16. Hu PJH, Chau PYK, Sheng ORL. Adoption of telemedicine technology by health care organizations: An exploratory study. J Org Comp Elect Com 2002; 12:197-221. https://doi. org/10.1207/S15327744JOCE1203_01.

17. Meher SK, Tyagi RS, Chaudhry T. Awareness and attitudes to telemedicine among doctors and patients in India. J Telemed Telecare 2009; 15:139-41. https://doi.org/10.1258/jtt.2009.003011.

18. El Gatit AM, Tabet AS, Sherief M, Warieth G, Abougharsa M, Abouzgaia $\mathrm{H}$. Effects of an awareness symposium on perception of Libyan physicians regarding telemedicine. East Mediterr Health J 2008; 14:926-30

19. Davis FD, Bagozzi RP, Warshaw PR. User acceptance of computer technology: A comparison of two theoretical models. Management Sci 1989; 35:982-1003. https://doi.org/10.1287/mnsc.35.8.982.

20. Mutahar AM, Norzaidi MD, Ramayah T, Isaac O, Alrajawy I. Integration of innovation diffusion theory (IDT) and technology acceptance model (TAM) to understand mobile banking acceptance in Yemen: The moderating effect of income. Int J Soft Comput 2017; 12:164-77.

21. Jensen SJ. An evaluation of GeoBEST contingency Beddown planning software using the technology acceptance model. From: https://scholar.afit.edu/etd/4426/ Accessed: Jul 2020

22. Liu ZY. An analysis of technology acceptance model-Exploring user acceptance and intension of taxi-hailing app in Shanghai. From: https://gupea.ub.gu.se/bitstream/2077/38592/1/gupea_2 077 38592_1.pdf Accessed: Jul 2020.

23. Hussein Z. Leading to intention: The role of attitude in relation to technology acceptance model in e-learning. Procedia Comput Sci 2017; 105:159-64. https://doi.org/10.1016/j.procs.2017.01.196.

24. Sniehotta FF. Towards a theory of intentional behaviour change: Plans, planning, and self-regulation. Br J Health Psychol 2009; 14:261-73. https://doi.org/10.1348/135910708X389042.

25. Davis F. Perceived usefulness, perceived ease of use, and user acceptance of information technology. MIS Quarterly 1989; 13:319-40. https://doi.org/10.2307/249008.

26. Aboelmaged MG. Predicting e-procurement adoption in a developing country: An empirical integration of technology acceptance model and theory of planned behavior, College of Business Administration, Ajman University of Science and Technology, Ajman, United Arab Emirates. Ind Manage Data Syst 2010; 110:392-414. https://doi.org/10.1108/02635571011030042.

27. Chau PYK, Hu PJ. Examining a model of information technology acceptance by individual professionals: An exploratory study. J Manag Inf Syst 2002; 18:191-229. https://doi.org/10.1080/0742 1222.2002.11045699. 